\title{
Lentivirus-mediated RNA interference of tripartite motif 68 inhibits the proliferation of colorectal cancer cell lines SW1116 and HCT116 in vitro
}

\author{
ZHEN TAN $^{1,2^{*}}$, XIAOSHUANG LIU ${ }^{1 *}$, ENDA YU $^{1}$, HANTAO WANG $^{1}$, \\ LIJUN TANG ${ }^{2}$, HAO WANG ${ }^{1}$ and CHUANGANG FU ${ }^{1}$ \\ ${ }^{1}$ Department of Colorectal Surgery, Changhai Hospital, Second Military Medical University, Shanghai 200433; \\ ${ }^{2}$ PLA Center of General Surgery, Chengdu Military General Hospital, Chengdu, Sichuan 610083, P.R. China
}

Received August 5, 2015; Accepted October 24, 2016

DOI: $10.3892 / \mathrm{ol} .2017 .5787$

\begin{abstract}
Colorectal cancer is one of the most common types of cancer worldwide. Previous studies have revealed that certain members of tripartite motif (TRIM) proteins are involved in carcin ogenesis regulation, but little is known about the function of TRIM68 in human colorectal cancer. To investigate the role of TRIM68 in colorectal cancer SW1116 and HCT116 cell lines, the present study conducted lentivirus-mediated knockdown against TRIM68 and demonstrated that depletion of TRIM68 notably inhibits colorectal cancer cell proliferation and colony formation ability. Cell cycle arrest in the G0/G1 phase and cycle accumulation in sub-G1 phase provided evidence that TRIM68 may participate in the regulation of colorectal cancer tumorigenesis. The results revealed the significant role of TRIM68 in regulating colorectal cancer cell mitosis and indicated that TRIM68 may be a promising therapeutic target.
\end{abstract}

\section{Introduction}

Malignant colorectal carcinoma (CRC) is one of the most devastating types of cancer worldwide. It is the second leading cause of cancer-associated mortality in Europe and the USA $(1,2)$. CRC causes 500,000 mortalities per year

Correspondence to: Dr Hao Wang or Dr Chuangang Fu, Department of Colorectal Surgery, Changhai Hospital, Second Military Medical University, 168 Changhai Road, Yangpu, Shanghai 200433, P.R. China

E-mail: wanghaohh@vip.126.com

E-mail: fugang416@126.com

"Contributed equally

Key words: lentivirus, RNA interference, tripartite motif containing 68 , proliferation, colorectal cancer worldwide (3), and it causes mortality in $1 / 3$ of patients (4). Despite improvement in CRC therapy, the disease-specific mortality remains high due to distant metastases and high recurrence rates $(5,6)$. Therefore, novel promising therapeutic molecules are urgently required.

Tripartite motif-containing (TRIM) proteins are recognized as a subfamily of E3 ubiquitin ligases as they contain a really interesting new gene (RING) finger domain (7). It is well known that ubiquitylation is an important type of post-translational modification in eukaryotic cells for selective elimination of short-lived proteins, which also have critical roles in human cancer (8). To date at least 76 known TRIM proteins have been identified and studied (9), and it has been demonstrated that TRIM family proteins are involved in a broad range of biological processes including cell growth, apoptosis, transcriptional regulation and tumorigenesis (10-21). Additionally, previous studies have indicated that TRIM members regulate carcinogenesis, providing positive or negative effects on tumor progression and oncogenesis regulation. Upregulated expression levels of TRIM24 (15,22), TRIM25 (23), TRIM27 (24), TRIM28 (25), TRIM29 (26), TRIM31 (27) and TRIM32 (28) can be observed in multiple types of cancer, including breast, ovarian, lung, bladder, colon and gastric cancer and myeloma (9). Notably gene deletion and reduced expression of TRIM8 $(29,30)$, TRIM13 $(31,32)$, TRIM33 $(33,34)$ and TRIM40 (35) were observed in cancer cells. A number of studies have attempted to elucidate the biological role of TRIM68 in the regulation of cancer; a study by Miyajima et al (36) found that the TRIM68 protein is significantly upregulated in human prostate cancer.

The present study sought to additionally investigate the expression patterns of TRIM68 in colorectal cancer cells by performing the RNA interference (RNAi) technique. To the best of our knowledge, this is the first time evidence has been provided that downregulated expression of TRIM68 suppresses the metastasis properties of colorectal cancer cells and induces cell cycle arrest in the G0/G1 phase. The present study shed light on the promising therapeutic value of TRIM68 against human colorectal carcinoma for future clinical applications. 


\section{Materials and methods}

Cell culture. Human embryonic kidney HEK293T cells and colorectal cancer HCT116 and SW1116 cell lines were obtained from the Cell Bank of Chinese Academy of Science (Shanghai, China). HCT116 and SW1116 cells were maintained in RPMI-1640 medium (cat. no. SH30809.01B+; Hyclone; GE Healthcare Life Sciences, Logan, UT, USA). HEK293T cells were cultivated in Dulbecco's modified Eagle's medium (DMEM; cat. no. SH30243.01B+; Hyclone; GE Healthcare Life Sciences). RPMI-1640 and DMEM were supplemented with $10 \%$ fetal bovine serum (cat. no. S1810; Biowest, Riverside, $\mathrm{MO}$, USA) and incubated at $37^{\circ} \mathrm{C}$, in a humidified atmosphere of $5 \% \mathrm{CO}_{2}$.

Lentiviral packaging and virus construction. A short hairpin RNA (shRNA) candidate sequence against the human TRIM68 gene (NCBI reference sequence, NM_01,8073.6) was screened to be the optimal sequence (5'-CAGAGTATT GTATGGGAGTTTCTCGAGAAACTCCCATACAATACT

CTGTTTTT-3', sequence 1). Concurrently the negative control short hairpin RNA (5'-GCGGAGGGTTTGAAAGAATAT CTCGAGATATTCTTTCAAACCCTCCGCTTTTTT-3')

was scrambled. The stem-loop-stem oligos (shRNAs) were synthesized, annealed, and ligated into the NheI/PacI-linearized shRNA vector pFH-L (Shanghai Hollybio Co., Ltd., Shanghai, China). DNA sequencing was performed to assess that the lentiviral shRNA expressing vectors were constructed without mismatched sequences. The generated plasmids were termed pFH-L-shTRIM68 and pFH-L-shCon.

HEK293T cells $\left(1.0 \times 10^{6}\right)$ were inoculated into $10 \mathrm{~cm}$ dishes and cultured for $24 \mathrm{~h}$ at $37^{\circ} \mathrm{C}$ to reach $>80 \%$ confluence. The medium was replaced with serum-free DMEM $2 \mathrm{~h}$ prior to transfection. The plasmids, consisting of $10 \mu \mathrm{g}$ of pFH-L-shTRIM68 or pFH-L-shCon, $7.5 \mu \mathrm{g}$ of pHelper plasmids pVSVG-I and $5 \mu \mathrm{g}$ of pCMV $\Delta \mathrm{R} 8.92$ (Shanghai Hollybio Co., Ltd., Shanghai, China), were added to the cells with a mixture of $0.95 \mathrm{ml}$ Opti-MEM (Gibco; Thermo Fisher Scientific, Inc., Waltham MA, USA) and $0.05 \mathrm{ml}$ Lipofectamine 2000 (Invitrogen; Thermo Fisher Scientific, Inc.). This mixture was then incubated for $8 \mathrm{~h}$ prior to replacing the medium with $10 \mathrm{ml}$ of complete DMEM (supplemented with $10 \%$ fetal bovine serum).

Lentiviral particles were harvested $96 \mathrm{~h}$ subsequent to transfection. HCT116 and SW1116 cells were cultivated in 6-well plates at a density of $5 \times 10^{4}$ cells/well and inoculated with recombinant lentiviruses (Lv-shCon or Lv-shTRIM68, Shanghai Hollybio Co.,Ltd.) at a multiplicity of infection (MOI) of 30 . The infection efficiency was determined by counting the numbers of green fluorescent protein (GFP)-expressing cells by fluorescence microscopy.

Reverse transcription-quantitative polymerase chain reaction (RT-qPCR) to monitor the downregulation efficiency of constructed lentivirus. Human colorectal cancer HCT116 or SW1116 cell lines were co-cultured with lentiviruses for 5 or 7 days, respectively. Reverse transcription was performed using quantitative RT-PCR kits (cat. no. kR103; Tiangen Biotech Co., Beijing, China). The mRNA expression level with or without vector transfection was detected, with $\beta$-actin acting as a normalizing control. The primers (5' to $\left.3^{\prime}\right)$ used for gene expression analysis were designed using NCBI Primer-BLAST and presented as follows: TRIM68 forward, 5'-GGAGCAAATCTTGGAGCTTG-3' and reverse, 5'-TGC ACACGTTTTCTGTCCTC-3'; $\beta$-actin forward, 5'-GTGGAC ATCCGCAAAGAC-3' and reverse, 5'-AAAGGGTGTAAC GCAACTA-3'. Infected colorectal cells were trypsinized and harvested 5 days subsequent to transduction. Total RNA was isolated using TRIzol reagent (Gibco; Thermo Fisher Scientific, Inc.) according to the manufacturer's protocol. In total, $1 \mathrm{mg}$ of total RNA was used to synthesize the first strand of cDNA using $200 \mathrm{U} / \mathrm{ml}$ SuperScript II RT (Invitrogen; Thermo Fisher Scientific, Inc.). Subsequently, 2 step RT-qPCR reactions were performed using the BioRad Connect Real-Time PCR platform (Bio-Rad Technologies, Inc., Hercules, CA, USA), which consisted of: Cycle $1(1 \mathrm{x}), 95^{\circ} \mathrm{C}, 1 \mathrm{~min}$; and cycle 2 with 40 repeated cycles, $95^{\circ} \mathrm{C}, 5 \mathrm{sec}$ and $60^{\circ} \mathrm{C}, 20 \mathrm{sec}$. Absorbance data were collected at the end of every extension $\left(60^{\circ} \mathrm{C}\right)$ and graphed using ABI 7500 Software v2.0.6 (Applied Biosystems, Inc., Carlsbad, CA, USA). The qPCR data were analyzed using the $2^{-\triangle \Delta C q}$ method (51).

Western blot analysis. Prior to applying western blot analysis, SW1116 cells were subcultured and infected at $37^{\circ} \mathrm{C}$ with recombinant lentiviruses for 4 days. The cells were rinsed with cold PBS twice, and tsubsequently lysed in cell lysis buffer containing $10 \mathrm{mM}$ EDTA, 4\% SDS, $10 \%$ glycine in 100 mM Tris-HCl (pH 6.8) (Shanghai Hollybio Co., Ltd.). Equal amounts of protein samples $(60 \mu \mathrm{g})$ were subjected to $10 \%$ SDS-PAGE in a Tris/HCl buffer (pH 7.4) and electrotransferred onto a polyvinylidene difluoride membrane (EMD Millipore, Billerica, MA, USA) at $300 \mathrm{~mA}$ for $1.5 \mathrm{~h}$. The membrane was blocked for $1 \mathrm{~h}$ in PBST buffer (PBS $\mathrm{pH} 7.4,0.05 \%$ Triton-100) containing $1 \%$ (w/v) bovine serum albumin at room temperature. The membrane was then probed with a rabbit anti-TRIM68 antibody (dilution, 1:500; cat. no. AP17177b; Abgent Biotech Co., Ltd., Suzhou, China) and rabbit anti-GAPDH antibody simultaneously (dilution, 1:3,000; cat. no. 10494-1-AP; Proteintech Group, Inc., Chicago, IL, USA) overnight at $4^{\circ} \mathrm{C}$, followed by 5 washes with PBST. Blots were then incubated with a secondary goat anti-rabbit horseradish peroxidase-conjugated antibody (dilution, 1:5,000; cat. no. SC-2054; Santa Cruz Biotechnology, Inc., Dallas, TX, USA) for $2 \mathrm{~h}$ at room temperature. The blots were developed using an enhanced chemiluminescence detection kit (Applygen Technologies, Inc., Beijing, China) in accordance with the manufacturer's protocol.

Cell proliferation assay and plate colony formation assay. HCT116 cells and SW1116 cells were exponentially cultured and infected with constructed lentiviruses at a MOI of 30 for $96 \mathrm{~h}$. Transfected cells were washed and re-seeded in 96-well plates at a density of 2,500 per well for HCT116 cells and 2,000 per well for SW1116 cells. Each well was treated with MTT solution dissolved in 10\% SDS, 5\% isopropanol and $0.01 \mathrm{M} \mathrm{HCl}$ for $10 \mathrm{~min}$ at $37^{\circ} \mathrm{C}$, and the formazan crystals were solubilized with $100 \mathrm{ml}$ of $10 \%$ SDS in $0.01 \mathrm{M} \mathrm{HCl}$ for $24 \mathrm{~h}$. Cell viability was determined by measuring absorbance at a wavelength of $595 \mathrm{~nm}$ under a microplate reader. Cell count and optical density readings using AxioVision 4.7 
microscopy software (Carl Zeiss AG, Oberkochen, Germany) were performed daily for 5 days.

Colony formation assays were performed by inoculating HCT116 and SW1116 cells into 6-well plates at the end of $96 \mathrm{~h}$ of lentivirus infection. In total, 500 cells per well of transfected HCT116 cells and 300 cells per well of SW1116 cells were cultured for 8 days. Colony cells were fixed with methanol and stained with $0.1 \%$ crystal violet. The number of colonies containing $>50$ cells was manually counted by microscopy (LSM710; Carl Zeiss AG).

Cell cycle analysis by flow cytometry. Cell cycle was analyzed by flow cytometry. Prior to cell cycle analysis, HCT116 cells were maintained in RPMI-1640 medium (cat. no. SH30809.01B+; Hyclone; GE Healthcare Life Sciences) and infected with the lentivirus for 5 days. Cells were harvested and washed twice in PBS, then fixed in $75 \%$ alcohol overnight at $4^{\circ} \mathrm{C}$ for permeabilisation. The next day, the cells were washed twice by cold PBS and resuspended in $1 \mathrm{ml}$ PBS with $100 \mathrm{mg}$ RNase A (Sigma-Aldrich; Merck Millipore, Darmstadt, Germany) for $30 \mathrm{~min}$ at $37^{\circ} \mathrm{C}$. The cells suspended in $1 \mathrm{ml} \mathrm{PBS}$ and $100 \mathrm{mg}$ propidium iodide (cat. no. 81845; Sigma-Aldrich; Merck Millipore, Darmstadt, Germany) prior to lucifugal incubation at $37^{\circ} \mathrm{C}$ for $30 \mathrm{~min}$. Samples were then analyzed on a FACS machine (Beckman, CA, USA) and detected in red fluorescence excitation with 20,000 counted.

Statistical analysis. All statistical analyses were performed using SPSS version 13.0 (SPSS, Inc., Chicago, IL, USA). The significant differences between groups were compared using Student's $t$-test, and data were expressed as the mean \pm standard deviation of 3 independent experiments. $\mathrm{P}<0.05$ was considered to indicate a statistically significant difference.

\section{Results}

Identification of recombinant lentiviral vectors for TRIM68 by GFP visualization. To investigate the biological role of TRIM68 in colorectal cancers, the present study performed a loss-of-function assay by RNAi: Control lentiviruses (Lv-shCon) and specific TRIM68-targeting lentiviruses (Lv-shTRIM68) were constructed. The most efficient type of shRNA expression cassette was selected and constructed into TRIM68-silencing lentiviral vector, and co-cultured with colorectal cancer cells (shTRIM68). Concurrently, negative blank controls of cells were cultured without lentiviral infection (Con). GFP expression in colorectal cancer cells was observed by fluorescent microscopy $96 \mathrm{~h}$ subsequent to infection. As shown in Fig. 1A, >80\% of SW1116 or HCT116 cells were GFP positive, indicating infection efficacy. To determine the silencing efficiency, the expression level of TRIM68 mRNA was detected by RT-qPCR. In Fig. $1 \mathrm{~B}$ and $\mathrm{C}$, the non-silencing lentivirus encoded by the irrelevant sequence had a negligible effect on TRIM68 expression, but the TRIM68-silencing lentivirus significantly downregulated the mRNA expression by $72.3 \%$ in the $\mathrm{SW} 1116$ group $(\mathrm{P}=0.000)$ and by $68.9 \%$ in the HCT116 group $(\mathrm{P}=0.001)$. In parallel, the protein level was monitored by western blot analysis (Fig. 1D), providing evidence that the protein expression of TRIM68 was noticeably depleted, while control groups (shCon) maintained a similar expression level.

The results of the present study demonstrate that the lentiviruses constructed provide knockdown efficiency and provide an efficient tool to investigate the knockdown effect of TRIM68 in colorectal cancer cells in vitro.

Depletion of TRIM68 represses cell proliferation and colony formation ability of colorectal cancer cells in vitro. Cell proliferation was monitored for 5 days subsequent to colorectal cancer HCT116 or SW1116 cells being infected with the shTRIM68 lentivirus. Solubilized formazan crystals were detected to evaluate cell viability in this assay. It was observed that cells infected with shCon lentivirus exhibited no alteration in cell proliferation and viability (Fig. 2; shCon vs. Con), while a marked inhibition in TRIM68 inhibition group was observed on day 5 compared to non-infected cells (shTRIM68 vs. Con; $\mathrm{P}=0.000)$, suggesting that knockdown of TRIM68 led to repressed cancer cell proliferation.

Malignant cancer cells possess a strong ability to form colonies in vitro (37). In the present assay, the colony of HCT116 and SW1116 cells was markedly smaller when infected with TRIM68-silencing lentivirus (Fig. 3A and B) and the respective colony numbers were significantly lower compared with the control cells (Fig. 3C and D, shTRIM68 vs. shCon; $\mathrm{P}=0.001$ ). The downregulation of TRIM68 significantly suppressed the colony formation capability of colorectal cancer cells.

The present study provided evidence that knockdown of TRIM68 by RNAi markedly suppresses the proliferation and colony formation ability of colorectal cancer cells in vitro.

TRIM68 silencing induces cell cycle arrest. To determine whether the decreased cell proliferation induced by knockdown of TRIM68 was due to cell cycle arrest, PI staining and flow cytometric analysis was performed. Fig. 4 shows that the G0/G1-phase DNA content in TRIM68-silenced cells (61.20\%) was significantly increased compared with that in non-silenced cells $(53.53 \%$; $\mathrm{P}=0.001)$. In addition, the $\mathrm{S}$ phase DNA content in the shTRIM68 group (22.85\%) was statistically decreased compared with that in the shCon group (29.12\%; $\mathrm{P}=0.000)$, which indicated that the cell cycle of TRIM68-silenced cells was arrested in the G0/G1 phase. These findings are in agreement with the cell growth inhibition observed in the proliferation assay, which suggests that the TRIM68 gene modulates the growth of human colorectal cancer cell via cell cycle control. The population of sub-G1 infected HCT116 cells was analyzed. Marked accumulation of sub-G1 group cells (Fig. 4C) indicated apoptosis was proceeding when TRIM68 was absent, leading to inhibited cell proliferation and colony formation reduction.

\section{Discussion}

The present study has demonstrated that TRIM68 acts as a potential tumor growth promoter in colorectal cancer. TRIM68 expression was observed to be positively associated with cancer cell proliferation and colony formation ability. More significantly, cancer cell cycle arrest by down-regulating endogenous expression of TRIM68 indicated that TRIM68 might be a promising therapeutic target for colorectal cancer. 


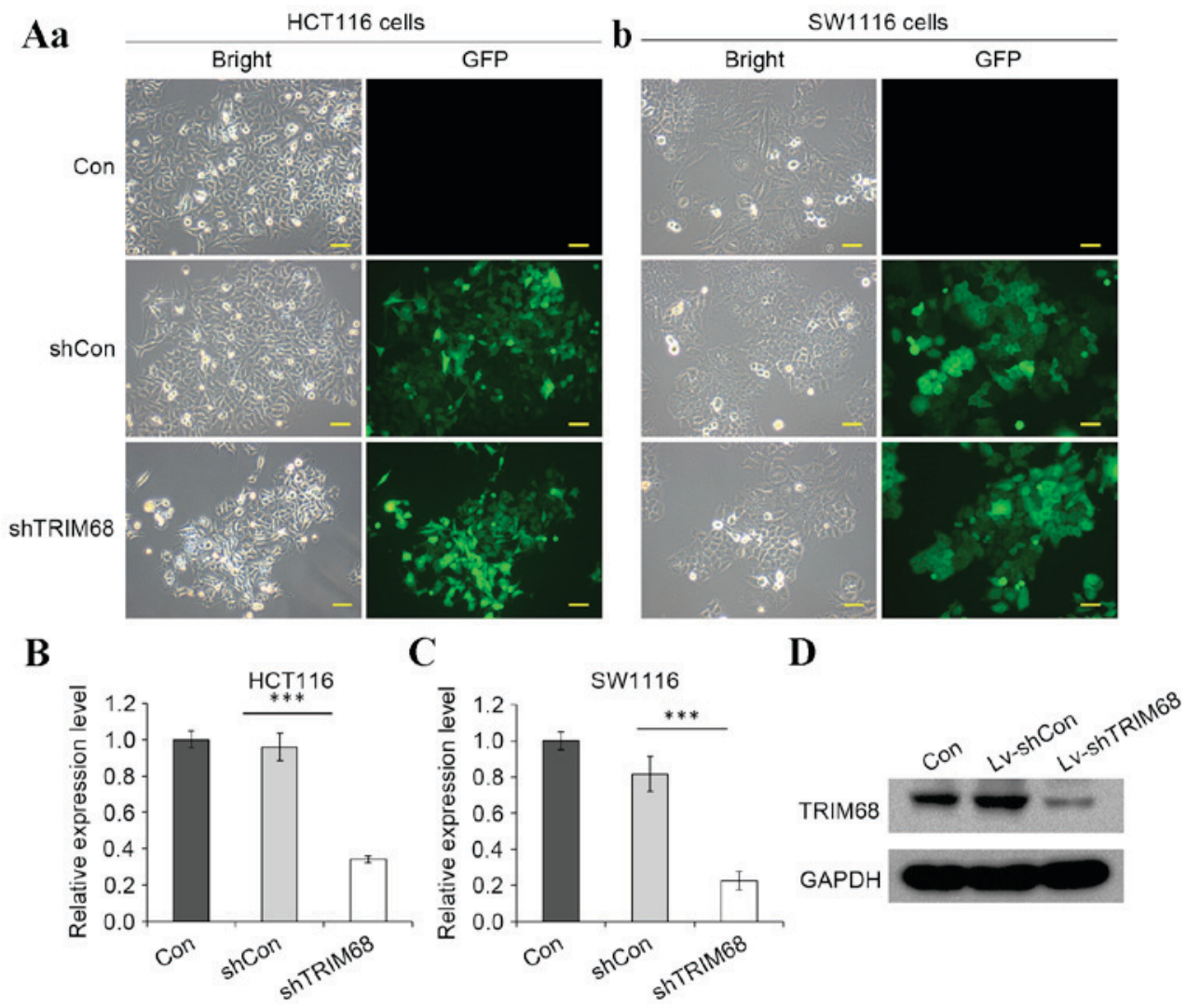

Figure 1. Lentivirus infection and knockdown efficiency of SMMC-7721 cells. (A) Bright field and fluorescence photomicrographs subsequent to transduction of (a) HCT116 and (b) SW1116 cells in Con, shCon and shTRIM68 groups, respectively. Relative mRNA expression level of TRIM68 in (B) HCT116 cells and (C) SW1116 cells determined by reverse transcription-quantitative polymerase chain reaction. (D) Protein expression level of TRIM68 in SW1116 cells determined by western blot analysis. Scale bar, $5 \mu \mathrm{m} .{ }^{* * * *} \mathrm{P}<0.001$, compared to shCon. TRIM68, tripartite motif containing 68; Con, control; shCon, negative control short hairpin RNA; shTRIM68, short hairpin RNA against TRIM68; GFP, green fluorescent protein.

A

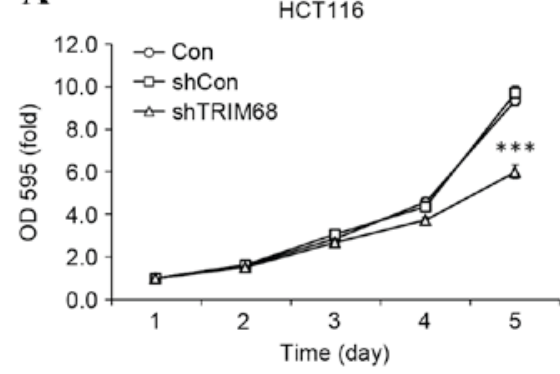

B

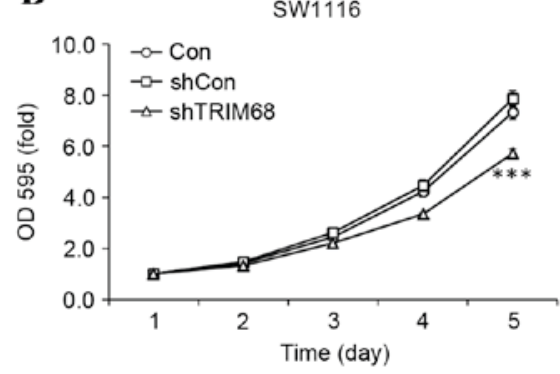

Figure 2. TRIM68 silencing inhibits colorectal cancer cell proliferation. The solubilized formazan crystal was examined in terms of optical density at absorbance $595 \mathrm{~nm}$. The viabilities of (A) HCT1116 cells and (B) SW1116 cells were determined respectively in Con, shCon and shTRIM68 groups. ${ }^{* * *} \mathrm{P}<0.001$, compared to shCon. TRIM68, tripartite motif containing 68; Con, control; shCon, negative control short hairpin RNA; shTRIM68, short hairpin RNA against TRIM68; OD, optical density.

RNAi has been utilized as an efficient therapeutic tool against human malignant carcinomas in previous decades (38-40), and lentivirus therapy is the most effective type of vehicle for gene transduction and integration (41) with lower immunogenicity compared with the adenovirus. The present study identified and functionally characterized the potential therapeutic value of knocking down the TRIM68 gene in human colorectal cancer cell lines SW1116 and HCT116. It was demonstrated that a downregulated TRIM68 expression level resulted in attenuated cell proliferation and colony formation. Cell cycle arrest and apparent apoptosis were also observed.
TRIM proteins, containing a RING finger, a B-box (B2) and a coiled-coil (CC) motif in the structure (7), may be classified into subfamilies I-XI on the basis of their structural variation $(10,42,43)$. TRIM68, structurally characterized as RING/B2/CC/PRY/Sprouty, has identical domains compared with TRIM22, TRIM27, TRIM39 and TRIM41 (42). The endogenous expression level of TRIM22, which is also termed stimulated transacting factor of $50 \mathrm{kDa}$, may be upregulated by p53 (44). Additionally, TRIM22 has been implicated in proliferation and differentiation of promyelocytic cells (45). TRIM27, also termed ret finger protein, may serve as a 
A

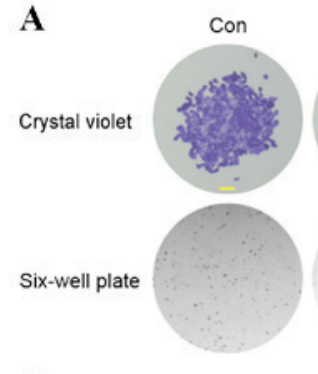

C

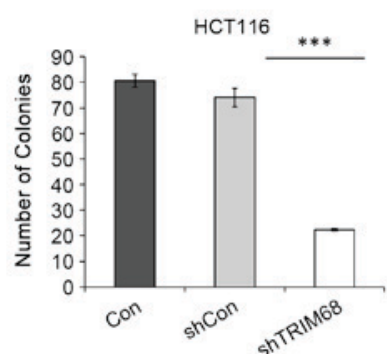

B
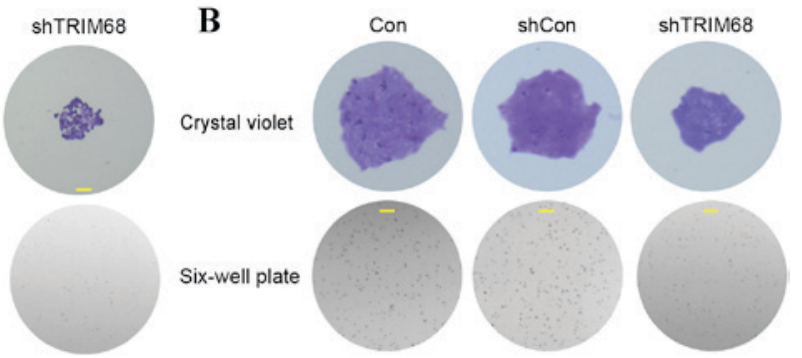

D

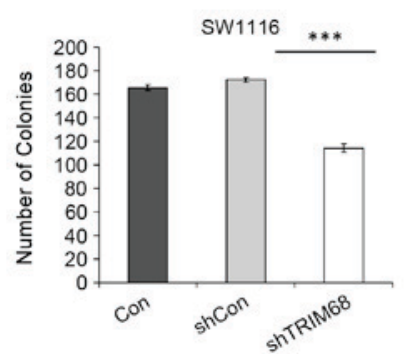

Figure 3. Downregulated expression of TRIM68 inhibits the colony formation ability of colorectal cancer cells. The colony formation of (A) HCT116 cells and (B) SW1116 cells in Con, shCon and shTRIM68 groups was detected in crystal violet under microscopy and bright field imaging in 6-well plates, respectively. The statistical analysis of colony numbers in (C) HCT116 and (D) SW1116 cells revealed that TRIM68 knockdown significantly inhibited colony formation capacity. ${ }^{* * * *} \mathrm{P}<0.001$, compared to shCon. TRIM68, tripartite motif containing 68; Con, control; shCon, negative control short hairpin RNA; shTRIM68, short hairpin RNA against TRIM68.

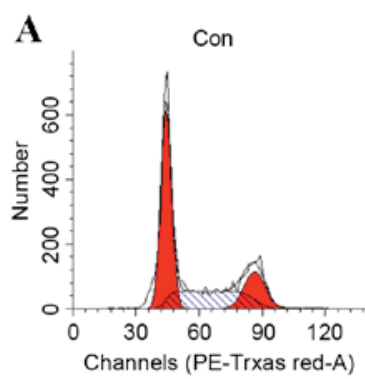

B

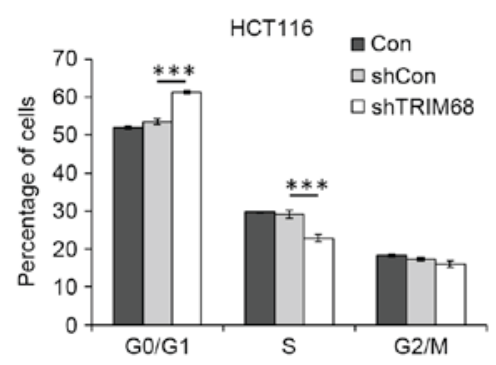

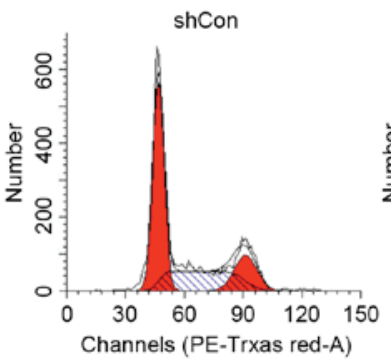

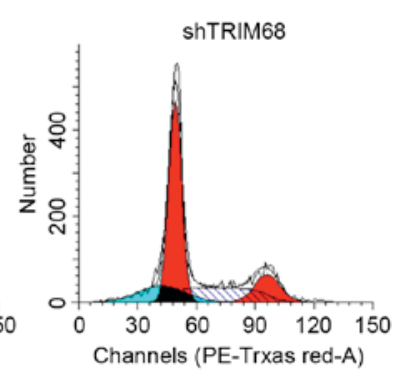

C

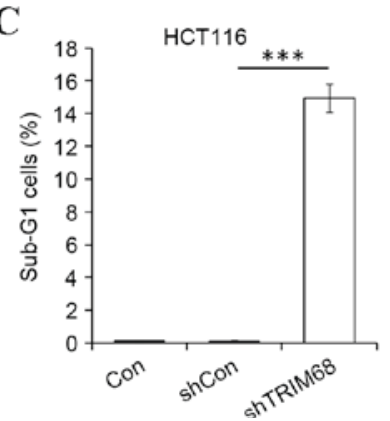

Figure 4. TRIM68 depletion arrests cell cycle progression. (A) Cell cycle distribution of HCT116 cells was determined by flow cytometry in Con, shCon and shTRIM68 groups, respectively. (B) The percentage of cells at the stages of G0/G1, S and G2/M. (C) Significant variation of cell cycle distribution in sub-G1 phase was observed. ${ }^{* * *} \mathrm{P}<0.001$, compared to shCon. TRIM68, tripartite motif containing 68; Con, control; shCon, negative control short hairpin RNA; shTRIM68, short hairpin RNA against TRIM68.

small ubiquitin-related modifier E3 ligase, which has been implicated in cell cycle regulation, apoptosis and endogenous protein transportation (46). TRIM27 is highly expressed in various cancer cells (47); its expression level correlates with ERBB2 protein expression in breast cancer (24), and studies have demonstrated that TRIM27 triggers apoptosis by the activation of JUN N-terminal kinases (48). TRIM41 is able to associate with protein kinase $\mathrm{C}$ to control the function of other proteins by phosphorylation (49). TRIM39 is able to associate and bind to modulator of apoptosis 1 and regulate caspase-dependent apoptosis (50). To date, a number of studies have investigated the molecular role of TRIM68 in cancer cells. Miyajima et al (36) provided evidence that TRIM68 interacts with androgen receptor (AR) and enhances its transcriptional activity in the presence of dihydrotestosterone. TRIM68 may be implicated as a cofactor for AR-mediated transcription and serve as a promising therapeutic target for prostate cancer. Additional studies will investigate the growth-related signaling 
molecules that are associated with aberrant expression levels of endogenous TRIM68.

In conclusion, the present findings indicated that TRIM68 has a role in colorectal cancer cell proliferation. Depletion of TRIM68 triggers cell cycle arrest and apoptosis. Lentivirus-mediated TRIM68 knockdown delivers efficient blocking of cancer cell colony formation, which indicates that TRIM68 is critical for colorectal cancer tumorigenesis. The present study revealed that TRIM68 may be a novel therapeutic target for the treatment of human colorectal cancer and deserves additional study.

\section{Acknowledgements}

The present study was supported by the National Natural Science Foundation of China (grant no. 81172307) and Youth Foundation of Chengdu Military General Hospital (grant no. 2016KC06, 41732C116).

\section{References}

1. Gaedcke J, Grade M, Camps J, Søkilde R, Kaczkowski B, Schetter AJ, Difilippantonio MJ, Harris CC, Ghadimi BM, Møller S, et al: The rectal cancer microRNAome-microRNA expression in rectal cancer and matched normal mucosa. Clin Cancer Res 18: 4919-4930, 2012.

2. Siegel R, Ward E, Brawley O and Jemal A: Cancer statistics, 2011: The impact of eliminating socioeconomic and racial disparities on premature cancer deaths. CA Cancer J Clin 61: 212-236, 2011.

3. Merika E, Saif MW, Katz A, Syrigos K and Morse M: Review. Colon cancer vaccines: An update. In Vivo 24: 607-628, 2010.

4. Cunningham D, Atkin W, Lenz HJ, Lynch HT, Minsky B, Nordlinger B and Starling N: Colorectal cancer. Lancet 375: 1030-1047, 2010

5. Xi ZW, Xin SY, Zhou LQ, Yuan HX, Wang Q and Chen KX: Downregulation of rho-associated protein kinase 1 by miR-124 in colorectal cancer. World J Gastroenterol 21: 5454-5464, 2015.

6. Nakamura Y, Nishi M, Fukuda Y, Ogino M and Kosuga H: Case of the multiple liver metastases from colon cancer obtained long-term disease-free survival with multimodality therapy. Gan To Kagaku Ryoho 39: 2228-2230, 2012.

7. Reymond A, Meroni G, Fantozzi A, Merla G, Cairo S, Luzi L, Riganelli D, Zanaria E, Messali S, Cainarca S, et al: The tripartite motif family identifies cell compartments. EMBO J 20: 2140-2151, 2001.

8. Yamaguchi H, Hsu JL and Hung MC: Regulation of ubiquitination-mediated protein degradation by survival kinases in cancer. Front Oncol 2: 15, 2012.

9. Hatakeyama S: TRIM proteins and cancer. Nat Rev Cancer 11: 792-804, 2011

10. McNab FW, Rajsbaum R, Stoye JP and O'Garra A: Tripartite-motif proteins and innate immune regulation. Curr Opin Immunol 23: 46-56, 2011.

11. Jensen K, Shiels C and Freemont PS: PML protein isoforms and the RBCC/TRIM motif. Oncogene 20: 7223-7233, 2001.

12. El Bougrini J, Dianoux L and Chelbi-Alix MK: PML positively regulates interferon gamma signaling. Biochimie 93: 389-398, 2011.

13. Tsai WW, Wang Z, Yiu TT, Akdemir KC, Xia W, Winter S, Tsai CY, Shi X, Schwarzer D, Plunkett W, et al: TRIM24 links a non-canonical histone signature to breast cancer. Nature 468: 927-932, 2010.

14. Herquel B, Ouararhni K, Khetchoumian K, Ignat M, Teletin M, Mark M, Béchade G, Van Dorsselaer A, Sanglier-Cianférani S, Hamiche A, et al: Transcription cofactors TRIM24, TRIM28, and TRIM33 associate to form regulatory complexes that suppress murine hepatocellular carcinoma. Proc Natl Acad Sci USA 108: 8212-8217, 2011.

15. Kikuchi M, Okumura F, Tsukiyama T, Watanabe M, Miyajima N, Tanaka J, Imamura M and Hatakeyama S: TRIM24 mediates ligand-dependent activation of androgen receptor and is repressed by a bromodomain-containing protein, BRD7, in prostate cancer cells. Biochim Biophys Acta 1793: 1828-1836, 2009.
16. Shimono Y, Murakami H, Hasegawa $Y$ and Takahashi M: RET finger protein is a transcriptional repressor and interacts with enhancer of polycomb that has dual transcriptional functions. J Biol Chem 275: 39411-39419, 2000.

17. Krutzfeldt M, Ellis M, Weekes DB, Bull JJ, Eilers M, Vivanco MD, Sellers WR and Mittnacht S: Selective ablation of retinoblastoma protein function by the RET finger protein. Mol Cell 18: 213-224, 2005.

18. Kano S, Miyajima N, Fukuda S and Hatakeyama S: Tripartite motif protein 32 facilitates cell growth and migration via degradation of Abl-interactor 2. Cancer Res 68: 5572-5580, 2008.

19. Kudryashova E, Kudryashov D, Kramerova I and Spencer MJ: Trim32 is a ubiquitin ligase mutated in limb girdle muscular dystrophy type $2 \mathrm{H}$ that binds to skeletal muscle myosin and ubiquitinates actin. J Mol Biol 354: 413-424, 2005.

20. Sho T, Tsukiyama T, Sato T, Kondo T, Cheng J, Saku T, Asaka M and Hatakeyama S: TRIM29 negatively regulates p53 via inhibition of Tip60. Biochim Biophys Acta 1813: 1245-1253, 2011.

21. Yuan Z, Villagra A, Peng L, Coppola D, Glozak M, Sotomayor EM, Chen J, Lane WS and Seto E: The ATDC (TRIM29) protein binds p53 and antagonizes p53-mediated functions. Mol Cell Biol 30: 3004-3015, 2010.

22. Chambon M, Orsetti B, Berthe ML, Bascoul-Mollevi C, Rodriguez C, Duong V, Gleizes M, Thénot S, Bibeau F, Theillet $C$ and Cavaillès V: Prognostic significance of TRIM24/TIF-1alpha gene expression in breast cancer. Am J Pathol 178: 1461-1469, 2011.

23. Sakuma M, Akahira J, Suzuki T, Inoue S, Ito K, Moriya T, Sasano H, Okamura K and Yaegashi N: Expression of estrogen-responsive finger protein (Efp) is associated with advanced disease in human epithelial ovarian cancer. Gynecol Oncol 99: 664-670, 2005.

24. Tezel GG, Uner A, Yildiz I, Guler G and Takahashi M: RET finger protein expression in invasive breast carcinoma: Relationship between RFP and ErbB2 expression. Pathol Res Pract 205: 403-408, 2009.

25. Yokoe T, Toiyama Y, Okugawa Y, Tanaka K, Ohi M, Inoue Y, Mohri Y, Miki C and Kusunoki M: KAP1 is associated with peritoneal carcinomatosis in gastric cancer. Ann Surg Oncol 17: 821-828, 2010.

26. Hawthorn L, Stein L, Panzarella J, Loewen GM and Baumann H: Characterization of cell-type specific profiles in tissues and isolated cells from squamous cell carcinomas of the lung. Lung Cancer 53: 129-142, 2006.

27. Sugiura T and Miyamoto K: Characterization of TRIM31, upregulated in gastric adenocarcinoma, as a novel RBCC protein. J Cell Biochem 105: 1081-1091, 2008.

28. Horn EJ, Albor A, Liu Y, El-Hizawi S, Vanderbeek GE, Babcock M, Bowden GT, Hennings H, Lozano G, Weinberg WC and Kulesz-Martin M: RING protein Trim32 associated with skin carcinogenesis has anti-apoptotic and E3-ubiquitin ligase properties. Carcinogenesis 25: 157-167, 2004.

29. Vincent SR, Kwasnicka DA and Fretier P: A novel RING finger-B box-coiled-coil protein, GERP. Biochem Biophys Res Commun 279: 482-486, 2000.

30. Caratozzolo MF, Valletti A, Gigante M, Aiello I, Mastropasqua F, Marzano F, Ditonno P, Carrieri G, Simonnet H, D'Erchia AM, et al: TRIM8 anti-proliferative action against chemo-resistant renal cell carcinoma. Oncotarget 5: 7446-7457, 2014.

31. Tomar D and Singh R: TRIM13 regulates ubiquitination and turnover of NEMO to suppress TNF induced NF- $\mathrm{KB}$ activation. Cell Signal 26: 2606-2613, 2014.

32. Tomar D, Prajapati P, Sripada L, Singh K, Singh R, Singh AK and Singh R: TRIM13 regulates caspase- 8 ubiquitination, translocation to autophagosomes and activation during ER stress induced cell death. Biochim Biophys Acta 1833: 3134-3144, 2013.

33. Aucagne R, Droin N, Paggetti J, Lagrange B, Largeot A, Hammann A, Bataille A, Martin L, Yan KP, Fenaux P, et al: Transcription intermediary factor $1 \gamma$ is a tumor suppressor in mouse and human chronic myelomonocytic leukemia. J Clin Invest 121: 2361-2370, 2011.

34. Wang E, Kawaoka S, Roe JS, Shi J, Hohmann AF, Xu Y, Bhagwat AS, Suzuki Y, Kinney JB and Vakoc CR: The transcriptional cofactor TRIM33 prevents apoptosis in B lymphoblastic leukemia by deactivating a single enhancer. Elife 4: e06377, 2015.

35. Noguchi K, Okumura F, Takahashi N, Kataoka A, Kamiyama T, Todo $\mathrm{S}$ and Hatakeyama S: TRIM40 promotes neddylation of $\mathrm{IKKg}$ and is downregulated in gastrointestinal cancers. Carcinogenesis 32: 995-1004, 2011. 
36. Miyajima N, Maruyama S, Bohgaki M, Kano S, Shigemura M Shinohara N, Nonomura K and Hatakeyama S: TRIM68 regulates ligand-dependent transcription of androgen receptor in prostate cancer cells. Cancer Res 68: 3486-3494, 2008.

37. Park CH, Bergsagel DE and McCulloch EA: Mouse myeloma tumor stem cells: A primary cell culture assay. J Natl Cancer Inst 46: 411-422, 1971.

38. Xue L, Hou J, Wang Q, Yao L, Xu S and Ge D: RNAi screening identifies HAT1 as a potential drug target in esophageal squamous cell carcinoma. Int J Clin Exp Pathol 7: 3898-3907, 2014.

39. Micklem DR and Lorens JB: RNAi screening for therapeutic targets in human malignancies. Curr Pharm Biotechnol 8: 337-343, 2007.

40. Seyhan AA: RNAi: A potential new class of therapeutic for human genetic disease. Hum Genet 130: 583-605, 2011

41. Grimm D and Kay MA: RNAi and gene therapy: A mutual attraction. Hematology Am Soc Hematol Educ Program: 473-481, 2007.

42. Short KM and Cox TC: Subclassification of the RBCC/TRIM superfamily reveals a novel motif necessary for microtubule binding. J Biol Chem 281: 8970-8980, 2006.

43. Ozato K, Shin DM, Chang TH and Morse HC III: TRIM family proteins and their emerging roles in innate immunity. Nat Rev Immunol 8: 849-860, 2008.
44. Obad S, Brunnström H, Vallon-Christersson J, Borg A, Drott K and Gullberg U: Staf50 is a novel p53 target gene conferring reduced clonogenic growth of leukemic U-937 cells. Oncogene 23: 4050-4098, 2004.

45. Hattlmann CJ, Kelly JN and Barr SD: TRIM22: A diverse and dynamic antiviral protein. Mol Biol Int 2012: 153415, 2012.

46. Chu Y and Yang X: SUMO E3 ligase activity of TRIM proteins. Oncogene 30: 1108-1116, 2011.

47. Cao T, Shannon M, Handel MA and Etkin LD: Mouse ret finger protein ( $\mathrm{rfp}$ ) proto-oncogene is expressed at specific stages of mouse spermatogenesis. Dev Genet 19: 309-320, 1996.

48. Dho SH and Kwon KS: The Ret finger protein induces apoptosis via its RING finger-B box-coiled-coil motif. J Biol Chem 278: 31902-31908, 2003.

49. Lee SS, Fu NY, Sukumaran SK, Wan KF, Wan Q and Yu VC: TRIM39 is a MOAP-1-binding protein that stabilizes MOAP-1 through inhibition of its poly-ubiquitination process. Exp Cell Res 315: 1313-1325, 2009.

50. Chen D, Gould C, Garza R, Gao T, Hampton RY and Newton AC: Amplitude control of protein kinase C by RINCK, a novel E3 ubiquitin ligase. J Biol Chem 282: 33776-33787, 2007.

51. Livak KJ and Schmittgen TD: Analysis of relative gene expression data using real-time quantitative PCR and the 2(-Delta Delta C(T)) Method. Methods 25: 402-408, 2001. 